\title{
Design and Implementation of Algorithms for Extraction and Representation of Morphological Features
}

\author{
Kapila Sharma \\ Department Of CA, SMIT, Rangpo, Sikkim, INDIA
}

\author{
Mohan P. Pradhan \\ Department Of CSE, SMIT, Rangpo, Sikkim, INDIA
}

\begin{abstract}
Automated information extracted from topographic sheet plays an important role in assisting researchers to extract identifiable features in the field of remote sensing and geographical information system. Extraction and representation of morphological patterns pertaining to an aspect of interest plays a pivotal role while making a quality assessment of the same. The confidence of the assessment procedures heavily relies on the effectiveness with which the patterns are extracted and represented. These extracted features can be used for performing various inferential analyses that aids in making qualitative as well as quantitative assessment of the features. This work aims at extracting various morphological features from topographic sheet automatically which further reduces time and effort requirement compared to that of traditional manual system.
\end{abstract}

\section{Keywords}

Topographic sheet, Extraction.

\section{INTRODUCTION}

Extraction and identification of morphological features into different identifiable categories is an important aspect of feature processing. In studies related to biometrics, minutiae play a pivotal role in making quality decisions related to various aspect of interest such as finger print, iris and many more. Minutiae in biometrics are specific points in a finger image. Minutiae are major components of morphological features. Minutiae include: Ridge ending- the abrupt end of a ridge, Ridge bifurcation- a single ridge that divides into two ridges, Short ridge, or independent ridge- a ridge that commences, travels a short distance and then ends. Island -a single small ridge inside a short ridge or ridge ending that is not connected to all other ridges. Ridge enclosure -a single ridge that bifurcates and reunites shortly afterward to continue as a single ridge, Spur -a bifurcation with a short ridge branching off a longer ridge. Crossover or bridge-a short ridge that runs between two parallel ridges, Delta -a Y-shaped ridge meeting, Core -a U-turn in the ridge pattern. For the identified features attribute details are to be associated which can be used for the purpose of making statistical inferences regarding the features. A repository for the same is to be created and its population is to be done.

\section{RELATED WORK}

Table 1. Related Work

\begin{tabular}{|c|l|l|}
\hline $\begin{array}{c}\text { Re } \\
\text { No }\end{array}$ & Name of Paper & \multicolumn{1}{|c|}{ Method } \\
\hline Contour line & $\begin{array}{l}\text { Presents a method for contour line } \\
\text { recognition starting from scanned } \\
\text { recognition from } \\
\text { scanned } \\
\text { topographic maps }\end{array}$ & $\begin{array}{l}\text { local geometric properties to } \\
\text { recognise countour lines based on }\end{array}$ \\
\hline
\end{tabular}

\begin{tabular}{|c|c|c|}
\hline & & $\begin{array}{l}\text { global topology of a generic } \\
\text { opographic map. }\end{array}$ \\
\hline [2] & $\begin{array}{l}\text { Recognition of } \\
\text { road and river } \\
\text { patterns by } \\
\text { relational } \\
\text { matching }\end{array}$ & $\begin{array}{l}\text { Automatic exterior orientatation of } \\
\text { images which uses relational } \\
\text { matching method.The structural } \\
\text { description of the images are } \\
\text { obtained by thresholding selected } \\
\text { channels of colour images. }\end{array}$ \\
\hline [3] & $\begin{array}{l}\text { Extraction of } \\
\text { stream channels } \\
\text { in high-resolution } \\
\text { digital terrain } \\
\text { images using } \\
\text { morphology }\end{array}$ & $\begin{array}{l}\text { An approach for the extraction of } \\
\text { stream channels from airborne laser } \\
\text { swath mapping(ALSM)data.Applies } \\
\text { morphological operations on an } \\
\text { ALSM DEM to detect stream } \\
\text { channels. The proposed method uses } \\
\text { small-scale morphology to provide } \\
\text { complementary results for } \\
\text { streamline locations over a small } \\
\text { catchment area. }\end{array}$ \\
\hline [4] & $\begin{array}{l}\text { An efficient } \\
\text { connectivity- } \\
\text { number-based } \\
\text { edge detection } \\
\text { method for binary } \\
\text { images }\end{array}$ & $\begin{array}{l}\text { A novel binary image edge detection } \\
\text { method is presented.it directly clears } \\
\text { the inner pixel of the images to } \\
\text { obtain the edges.connectivity } \\
\text { number were sought as } \\
\text { detectors, those pixels that have zero } \\
\text { connectivity-number were } \\
\text { eliminated as inner pixels from the } \\
\text { image. }\end{array}$ \\
\hline [5] & $\begin{array}{l}\text { Automatic } \\
\text { extraction of } \\
\text { contour lines } \\
\text { from topographic } \\
\text { maps }\end{array}$ & $\begin{array}{l}\text { An algorithm to extract countour } \\
\text { lines from coloured images of } \\
\text { scanned topographic maps. First } \\
\text { segment the colour images using } \\
\text { adaptive threshholding to extract } \\
\text { basic countour structure. Noise in the } \\
\text { image is removed using } \\
\text { morphological operations. }\end{array}$ \\
\hline
\end{tabular}

\section{METHODOLOGY}

the approach applied for extraction and representation of morphological features various parts of the image are represented with zeros and ones in matrix representation which define the shape of the image. The matrix is scanned in all possible locations traversing all pixels. The structural information of the image is justified with the pixel set to one (foreground) and the pixel set to zero (background) do not have any relevance to the feature of interest. 


\begin{tabular}{|l|l|l|l|l|l|l|l|l|l|}
\hline 1 & 0 & 0 & 0 & 0 & 1 & 0 & 0 & 0 & 0 \\
\hline 0 & 0 & 0 & 1 & 0 & 0 & 0 & 0 & 0 & 0 \\
\hline 0 & 0 & 0 & 1 & 0 & 0 & 0 & 0 & 0 & 0 \\
\hline 0 & 0 & 0 & 1 & 0 & 0 & 0 & 0 & 0 & 0 \\
\hline 0 & 0 & 0 & 1 & 0 & 0 & 1 & 1 & 1 & 0 \\
\hline 0 & 0 & 0 & 0 & 0 & 1 & 0 & 0 & 1 & 0 \\
\hline 0 & 0 & 1 & 0 & 0 & 1 & 0 & 0 & 0 & 1 \\
\hline 0 & 1 & 0 & 0 & 1 & 0 & 0 & 0 & 1 & 0 \\
\hline 1 & 0 & 0 & 1 & 0 & 0 & 0 & 0 & 0 & 1 \\
\hline 0 & 0 & 0 & 0 & 0 & 0 & 0 & 0 & 0 & 1 \\
\hline
\end{tabular}

Figure 1: traversal process

\begin{abstract}
Algorithm Description: traverse a matrix with 0's and 1's and with every 1 encountered check for presence of features enclosures, lines, points.
\end{abstract}

Variable description:

$$
\begin{array}{ll}
\text { Input } & : \text { mat [size][size] } \\
\text { Output } & : \text { mat [size][size] }
\end{array}
$$

Processing: i j

Pre : mat [size][size ] is a matrix of size 15 by 26

Post : enclosures, lines, points detected and coordinates displayed

Step 0: start

Step 1: call check closure ()

Step2: call check line ()

Step3: check point ()

Step 4: stop

\section{Algorithm _check closure ( )}

Algo_description: Method that checks if the given point in the matrix is a part of and to closure identifies the closure.

Variable Description:

Input : mat [size][size]

Output : mat [size][size]

Processing: i j

Pre : mat [size][size ] is a matrix of with 0's and 1 's

Post : mat [i][j] with the closures detected and coordinates displayed

Step 0: start

Step 1: [read] i, j, row no. col no.

Step2: call visit points [size][size]

2.1 [test condition] if neighbor [0]==begin $\mathrm{x}$ and neighbor $[1]==$ begin $y$ and visited length $>2$

2.1.1closure [no closure].pos
2.2 [switch case] check for positions $(\mathrm{x}, \mathrm{y}+1),(\mathrm{x}+1, \mathrm{y}+1)$ $(\mathrm{x}+1, \mathrm{y}),(\mathrm{x}+1, \mathrm{y}-1),(\mathrm{x}, \mathrm{y}-1),(\mathrm{x}-1, \mathrm{y}-1),(\mathrm{x}-1, \mathrm{y}),(\mathrm{x}-1, \mathrm{y}+1)$

Step 3: stop

\section{Algorithm _checkline ()}

Algo_description: method to check if the given point in the matrix forms lines

Variable description:

$\begin{array}{ll}\text { Input } & : \text { mat [size][size] } \\ \text { Output } & : \text { mat [size][size] }\end{array}$

Processing $\quad: \mathrm{ij}$

Pre $\quad$ : mat [size][size ] is a matrix of 0 's and 's

Post : number of lines formed by each non zero element

Step 0: start

Step 1: [initialize] temp $=0$

Step2: [initialize] temp_1=0

2.1[test condition] if mat[x][y].value==1 and mat[x][y].is used $==0$

2.1.1 [test condition] if mat $[\mathrm{x}][\mathrm{y}+1] . v a l u e==1$ and $\operatorname{mat}[\mathrm{x}][\mathrm{y}+1]$.is used $==0$

2.1.2 [test condition] if mat $[\mathrm{x}+1][\mathrm{y}]$. value $==1$ and $\operatorname{mat}[\mathrm{x}+1][\mathrm{y}]$.is used $==0$

2.1.3[test condition] if $\operatorname{mat}[x+1][y-1] . v a l u e==1$ and $\operatorname{mat}[\mathrm{x}+1][\mathrm{y}-1]$.is used $==0$

2.1.4[test condition] if mat $[\mathrm{x}+1][\mathrm{y}+1] \cdot$ value $==1$ and $\operatorname{mat}[\mathrm{x}+1][\mathrm{y}+1]$.is used $==0$

$$
\text { 2.1.5[set] mat[x][y].is used }=1
$$

Step3: stop

\section{Algorithm _checkpoint ()}

Algo_description: method to check if the point in the matrix forms points

Variable Description:

Input $\quad$ : mat [size][size] 
Output as coordinates Processing Pre

Post coordinates

Step 0: start
Step 1: [test condition] mat[x][y].value Step2: [test condition] if check used( $\mathrm{x}, \mathrm{y})$

2.1 [set] points [no points].pos [0] $=\mathrm{x}$

2.2 [set] points [no points].pos [1] =y 2.2.1[increment] no points

2.3 [set] mat[x][y].is used $=1$ step3: stop

\section{RESULT AND DISCUSSION}

Table 2. Result and Discussion

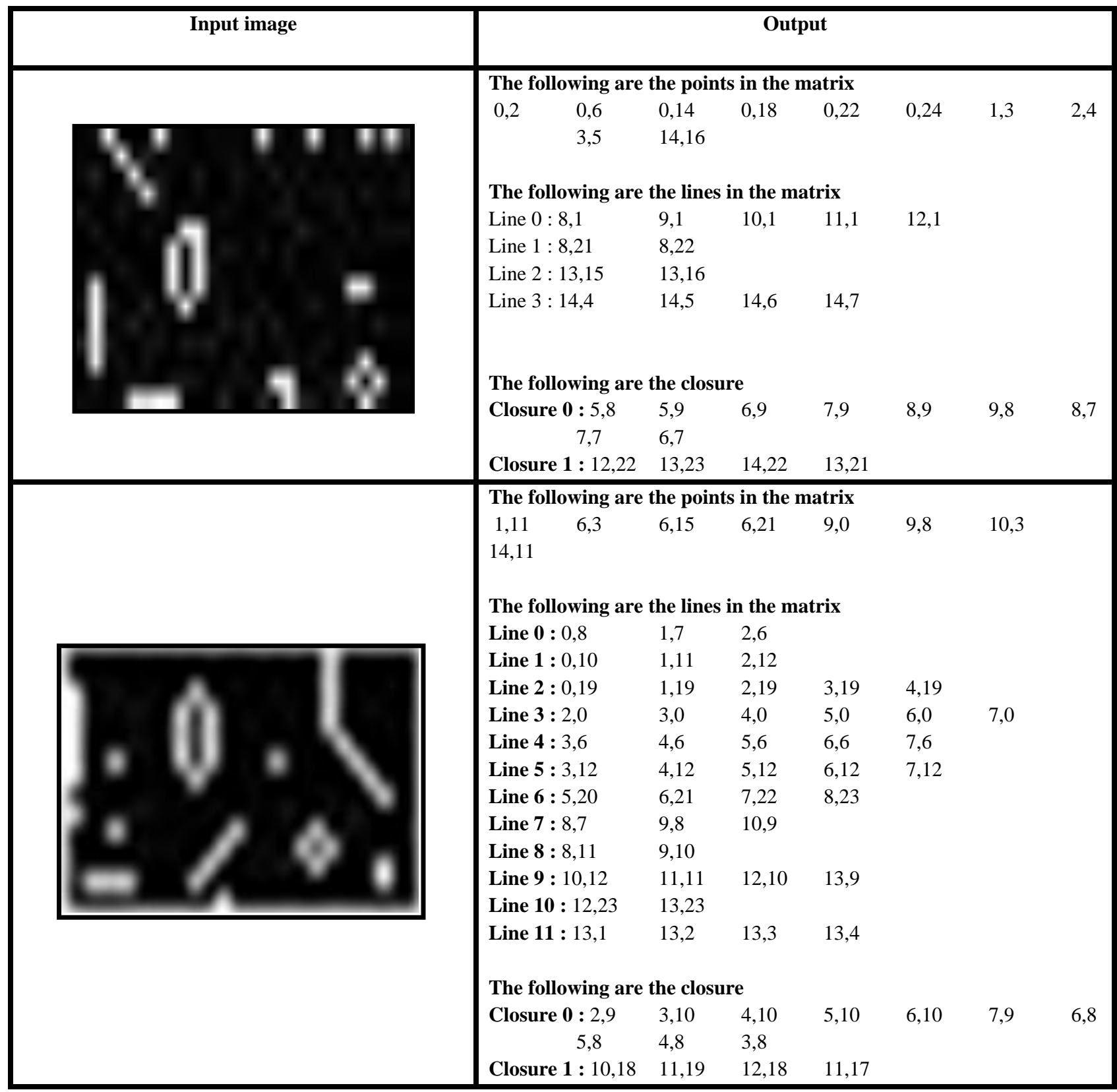

\section{CONCLUSION}

The algorithms extraction and identification of morphological features were successfully implemented.

The algorithm implemented for identifying morphological features were capable of identifying feature like enclosure, ridge and points. This implementation can be further extended to bifurcation.
Identification of morphological features: To identify the morphological features like the enclosure, lines, points. The user is required to input the binary matrix (input image) from

which one wishes to recognize the various features which were successfully identified and stored with coordinate points. 


\section{REFERENCES}

[1] Salvatore, Spinello, and Pascal Guitton. "Contour line recognition from scanned topographic maps." Journal of WSCG 12.1-3 (2004).

[2] Haala, Norbert, and George Vosselman. "Recognition of road and river patterns by relational matching." International Archives of Photogrammetry and Remote Sensing 29 (1993): 969-969.

[3] Cho, Hyun-chong, et al. "Extraction of stream channels in high-resolution digital terrain images using morphology." Geoscience and Remote Sensing Symposium, 2006. IGARSS 2006. IEEE International Conference on. IEEE, 2006.
[4] Zhang, Wen-Ming, and Sun-An Wang. "An efficient connectivity-number-based edge detection method for binary images." Machine Learning and Cybernetics, 2005. Proceedings of 2005 International Conference on. Vol. 9. IEEE, 2005.

[5] Gul, Sadia, and Muhammad Faisal Khan. "Automatic extraction of contour lines from topographic maps." Digital Image Computing: Techniques and Applications (DICTA), 2010 International Conference on. IEEE, 2010

[6] Jinyang, Du, and Zhang Yumei. "Automatic extraction of contour lines from scanned topographic map." Geoscience and Remote Sensing Symposium, 2004 IGARSS'04. Proceedings. 2004 IEEE International. Vol. 5. IEEE, 2004. 